\title{
La educación, ¿un asunto de medios? *
}

Guillermo Bustamante Zamudio ${ }^{27}$

\section{Resumen}

Mientras aprender es de animales y de humanos, enseñar es prácticamente de humanos: la sociedad es un dispositivo pedagógico que se reproduce si enseña su funcionamiento, que es construido, no-natural. Para esto, recurre a distintos medios, que se constituyen en una condición de posibilidad de la educación, pero no en algo que la determina, como se quiere mostrar a veces a propósito de las relaciones entre educación y ciertos medios modernos. Cada educación obedece a sus propias determinaciones, no se puede comparar con otra de cara a un valor transcultural. En nuestro caso, muchas veces los medios se usan para "hacer fácil lo difícil", cuando en el ámbito del conocimiento -que la escuela se propone desarrollar- "lo que es fácil de enseñar es inexacto": lo enseñado con los atractivos de los medios puede ser lejano al conocimiento, en tanto no causa preguntas; en esto, un buen medio no remplaza a un maestro. La sociedad dispone de los medios que ha creado para responder a sus propias exigencias, de manera que lo interesante es entender esa cultura y no obnubilarnos por las propiedades de unos medios que no pueden hacer más que aquello que es posible en esa cultura. La cantidad de información y la velocidad de su transmisión no son valores en sí mismos.

\section{Palabras claves}

Cultura - medios - conocimiento - educación

\section{Summary}

While learning is a possibility of animals and humans, teaching is only human. Society is a pedagogical device that reproduces itself by teaching its functioning, which is built, not natural. In order to do that, society uses different media, which are conditions for the possibility of education but not its determinants, -as they sometimes are presented while discussing the relationships between education and certain modern media-. Due to its transcultural value, each education follows its own determinants, which cannot be compared with one another. In our case, many media are used to "make easy what is considered difficult" even though in the context of knowledge -which is what schools try to develop - "what is easy to teach is inexact". What is taught by means of the appealing features of the media may be far from what knowledge really is, since it does not cause questioning. In this respect, a good medium does not replace a teacher. Society uses the media that has created in order to fulfil its own needs, so what is really interesting is to understand that culture. We should not become blinded by the properties of a medium that cannot do anymore than what is possible in its own culture. The quantity of information and its speed of transmission are not values by themselves.

\footnotetext{
- Artículo escrito para el seminario Uso pedagógico de los medios audiovisuales en el aula. Cali, noviembre 12 de 2003. Fue recibido el 16 de febrero de 2004 y arbitrado el 23 de marzo de 2004.

${ }^{27}$ Profesor Departamento de Posgrados, Facultad de Educación, Universidad Pedagógica Nacional. E-mail: bustama@colnodo.apc.org
} 


\section{Key words}

Culture - media - knowledge - education

\section{Educación y medios ¿es lo mismo?}

No se puede decir que aprender sea algo exclusivo de los humanos: los animales aprenden en función inversa al peso que tienen sus respuestas instintivas. Pero la idea de enseñar sí es prácticamente humana. En los animales sólo se han verificado incipientes procesos de enseñanza en algunos mamíferos superiores: determinados chimpancés africanos, por ejemplo, que derivan parte de su sustento de frutos que es necesario partir con ayuda de un objeto contundente, "enseñan" a sus crías una conducta que no es instintiva. En cambio, en las sociedades humanas, todo es construido, no-natural y, en consecuencia, arbitrario: el lenguaje, la alimentación, la sexualidad, las costumbres, las normas... y por eso, si se quiere que la vida social siga existiendo, todas estas prácticas deben ser enseñadas y, en consecuencia, deben ser aprendidas. La sociedad es un gran dispositivo que se reproduce en la medida en que enseña sus maneras de funcionar, desde amarrarse los zapatos hasta codificar mensajes cifrados, dirigidos a culturas extraterrestres que, sin embargo, no sabemos si existen. En este sentido, y siguiendo a Basil Bernstein, puede afirmarse que las sociedades humanas se basan en el dispositivo pedagógico.

Si esto es así, la educación —no la escuela, que es un mecanismo específico, más o menos reciente, para llevar a cabo algunas de las funciones educativas - ha existido siempre que ha habido sociedad humana, y siempre ha tenido que servirse de los mecanismos necesarios y disponibles para hacerlo.

Si educación es lo que ocurría cuando Sócrates se paseaba discutiendo con sus contertulios sobre lo sagrado y lo profano. Si es lo que ocurre cuando en la maloca un adulto le cuenta, a un muchacho, que ya está candidatizado para ser hombre, la historia de todas las cosas, según lo entiende la cultura... si estos eventos son educativos, allí lo determinante es justamente aquello de lo que se habla, los mecanismos de persuasión o disuasión, las ejemplificaciones, las maneras para verificar si está teniendo lugar la comprensión, las formas de pedir otra explicación, de tratar de interpretar algo con esas herramientas, las aplicaciones, los ritos en los que se inscribe, los saberes a los que se recurre, las autoridades que se traen a cuento, los ejercicios que se estiman convenientes para familiarizar al aprendiz con la habilidad que se espera desarrollar, la clasificación de los temas según la edad, el sexo, etc. Sin asuntos como estos, no hay educación.

En todos los casos, estas interacciones sociales han tenido que recurrir a medios: un fragmento de madera que se recoge del piso para hacer unos trazos; objetos hechos a semejanza de otros que resultan inalcanzables, peligrosos, invisibles o muy grandes; superficies especiales para dibujar o marcar; instrumentos para marcar, tintas; espacios específicos donde cierta actuación se circunscribe y se hace visible... En este punto, hemos de entender que la educación es versátil: de un lado, a falta de algún recurso, se buscará un reemplazo, y, de otro lado, ante un nuevo recurso, adaptará sus formas. Así, la diferencia entre la tiza y el marcador para tablero acrílico no es educativa; en cambio, sí es educativa la diferencia entre relatar ciertas cosas como historia de la cultura, de manera oral, a cargo de una persona específica, a cierta edad del aprendiz, en un sitio sagrado, y contarla como cuentos en las cartillas destinadas a que los indígenas aprendan a leer. 
Por todo esto, es necesario plantear que la educación ha estado ligada de manera indefectible a los medios y que ellos constituyen una condición de posibilidad de la educación (una condición permanente de su realización), pero no algo que la determina. $Y$, además, que esos medios dependen de la cultura que los utiliza (no necesariamente que los produce). De manera que si hoy los mass media nos parecen tan importantes para la educación es por efecto de una inversión, muy propia de nuestra época, en la que un medio se eleva al estatuto de especificidad. Medio que se puede comercializar, mientras que la especificidad elude hasta cierto punto ese régimen (comercializar el conocimiento, por ejemplo, produce el efecto de que lo comercializado pueda ya no ser el conocimiento sino la "información"). Si esto es así, podríamos estar dejando escapar lo importante -quizá nos interesa evadirlo- y haciendo esfuerzos e inversiones en lo secundario (lo cual no deja de rendir sus propios dividendos en niveles no propiamente educativos).

El gobierno distrital en Bogotá, por ejemplo, invirtió -a expensas de la investigación educativa- varios miles de millones de pesos en la serie Francisco el matemático. El propósito -inobjetable, como todo buen propósito- era educar a muchas personas, más de lo que podría hacer la escuela, en el tema de los valores, algo que la escuela tal vez no haría mejor que los medios ${ }^{28}$. Pues bien, al cabo de un tiempo lo único que tenemos con certeza es otra telenovela y un dinero oficial invertido para posicionar un producto cuyos beneficios económicos son para el capital privado. No hay pruebas de que tengamos un país más "educado en valores" gracias a la telenovela, pretensión que parece desconocer la complejidad de cómo se gesta lo que llamamos "valores" ${ }^{29}$.

Por efecto de la época en que vivimos, al hablar de medios parece que la referencia fueran fundamentalmente los mass media, los medios masivos de comunicación. En relación con los medios audiovisuales en la educación, el asunto apuntaría entonces a la televisión, a las cintas de video y a los aparatos que las graban y reproducen; y, por extensión, también al lenguaje propio en que tales videos son diseñados. De tal manera, los trozos de piedra pizarra en los que escribían los niños a comienzos del siglo XX en Colombia (y que borraban con saliva) ya no se nos presentan a la "altura" de los medios, ni siquiera se los consideraría como tales.

En conclusión, se abren dos alternativas: a) Si los medios son los mass media, sería forzoso afirmar que antes de su existencia -que es contemporánea-, no hubo educación, pues la educación se hace a través de medios; y entonces los medios serían determinantes en lo educativo. $\mathrm{Y}$ b) Si los medios son mecanismos usados para comunicarse —en todas las épocas_- y si siempre hubo educación, sería forzoso afirmar que la educación siempre ha estado relacionada con los medios, pero que no son ellos los que definen su especificidad.

\section{2. ¿Qué compromete la educación?}

Las diversas miradas sobre la educación intentan, en todas las épocas y con los sesgos de sus perspectivas históricas y conceptuales, responder esa pregunta que continúa abierta. De tal manera, aquí no pretendemos responderla de manera definitiva, sino

${ }^{28}$ Álvarez (2003) muestra que esta es una de las formas como en educación se asumió la afrenta de la aparición de la radio a comienzos del siglo XX en Colombia, de manera que no sólo no se trata de algo novedoso, sino que se trata de una posición que no ha visto cumplidos sus objetivos.

29 De nuevo, Álvarez (2003) muestra cómo la relación entre medios y educación siempre se ha producido independientemente de los propósitos.

Digitalizado por RED ACADEMICA 
plantear tres asuntos —el conocimiento, la interacción y la comunicación- que hoy, al tenor de ciertos modelos explicativos, nos parecen comprometidos en los actos educativos.

\section{El conocimiento}

Cuando un adulto bosquimano actúa delante de los niños, mostrando las maneras como las diferentes especies de animales se comportan, estamos ante un proceso educativo. Los medios, a lo sumo, son algunos objetos como ramas o paja. En la misma época, pero en otro sitio, se les muestra a los alumnos, en una grabación de video, el comportamiento animal, mediante imágenes entre las cuales hay algunas que el bosquimano está imposibilitado de representar (lo que ocurre dentro de la madriguera, animales microscópicos, etc.). A partir de esta diferencia, cualquiera podría apresurarse a decir que nuestra educación es mejor que la que se dispensa en el desierto de Kalahari. Pero no: cada una obedece a sus propias determinaciones, a sus propias necesidades, se ha ido acomodando en relación con una cultura (allá, más le vale a un niño saber cómo aparecer más alto delante de una hiena, que saberse la tabla del 9). Las formas de educación mencionadas son incomparables de cara a un valor transcultural. Es decir, no dan lugar a un juicio en el que se diga que una es mejor que la otra.

No sabemos si los niños en ese desierto, durante la representación, ven los animales que el adulto imita; no sabemos si también ven la representación como tal. Pero en nuestro caso, por ser nuestra cultura, sabemos que los medios tocan otro tipo de emociones, además del conocimiento, que es a lo que supuestamente apuntarían en última instancia. Si la educación compromete el conocimiento, como solemos pretender, es necesario pensar los medios en relación con esa especificidad: ¿es indiferente el conocimiento a los medios empleados para su "transmisión" ${ }^{30}$ ?

Desde esta perspectiva, la bondad de los medios ya no parece indefectible. Y no solamente por los límites que ellos puedan tener, sino por la utilización que de ellos se hace. Si está en juego el conocimiento, la pregunta no es cuál es el mejor medio para lograrlo, sino cuál es la posición en la que está quien usa el medio, quien diseña la unidad instruccional a través de un medio. En este punto, resulta muy iluminativo Gaston Bachelard, para quien la posibilidad de representar algo es uno de los obstáculos para su comprensión ${ }^{31}$. Muchas instituciones educativas tienen una maqueta de alambre y pelotas de icopor que "representa" el átomo. Pues bien, este epistemólogo francés dice que el átomo en la física es una lucha contra la representación. Según él, el átomo es más bien un puñado de argumentos. Quien entiende el átomo con ayuda de dibujos y maquetas, no ha entendido el átomo de la física, sino el "átomo escolar", el que sirve para responder exámenes, pero que en la física es justamente un obstáculo, algo que no representa un conocimiento.

Si en la escuela se trata de "hacer fácil lo difícil", en el ámbito del conocimiento "lo que es fácil de enseñar es inexacto", como dice Bachelard [1940: 24]. Esto nos muestra la escuela ya no como un ámbito neutral en el que casi todo vale ante el encomiable propósito de enseñar a las nuevas generaciones lo que nos legaron las anteriores, sino

${ }^{30}$ Los medios parecen más cercanos a una idea de "transmisión" del conocimiento que a una de "construcción" del conocimiento.

31 Los intentos de representar las abstracciones materializan un estado previo a aquel que permite al espíritu sustraerse de la intuición, de la experiencia inmediata, que polemiza abiertamente con la realidad (Bachelard, 1948: 11). 
como un ámbito en el que se puede ir a favor o en contra de la especificidad del conocimiento, dependiendo de la posición del enseñante. Excelentes medios se pueden utilizar, por ejemplo, para mostrar que la naturaleza está organizada según los principios humanos. Ciertos programas sobre animales, que son de una factura insuperable, hechos con las últimas tecnologías y con un manejo excelente del lenguaje visual, muestran, sin embargo, una naturaleza antropomorfa, distinta de la naturaleza como objeto de conocimiento de la ciencia ${ }^{32}$.

Es igual de oscurantista poner la Tierra o el Sol en el centro del sistema solar, pues ninguna de las dos opciones objeta la idea de "centro". De manera que con ayuda de nuestras maquetas escolares sobre el sistema solar, los niños recitan la posición de los planetas, se los representan imaginariamente, pero, acto seguido (independientemente de que pongan el Sol en el centro), si se les pregunta para dónde se va el sol cuando anochece, perfectamente responden: "se esconde detrás de las montañas"33. Ya Kepler había verificado, contra la evidencia de los siglos anteriores, que el Sol está en uno de los focos de la elipse que describe el movimiento de la tierra, planeta que no tiene dos movimientos, como dice la escuela, sino 17. Y no se trata de informar bien o mal, de cambiar 2 por 17, o de sacar al Sol del centro de la maqueta hacia un foco de la elipse, sino de la forma como en cada caso nos relacionamos con el conocimiento.

Ernesto Sábato fue invitado, durante las preguntas posteriores a una conferencia, a explicar la teoría de la relatividad a un auditorio de no especialistas. Hizo una demostración matemática ante su público, pero éste le manifestó no haber comprendido. Entonces se apoyó en unos ejemplos para resumir un poco el procedimiento matemático. No obstante, el público siguió manifestando su incomprensión. El escritor prescindió, pues, de fórmulas y utilizó sólo ejemplos. Ahora sí, el público dijo haber comprendido. Entonces, Sábato les hizo saber que habían comprendido algo diferente de la teoría de la relatividad, que estaba realmente en la primera explicación, pues era irreductible a ejemplos ${ }^{34}$.

La educación puede enseñar los programas llamados "procesadores de palabras". Son efectivamente herramientas muy importantes. El problema es que resulta imprescindible tener algo que decir para que esa importancia se materialice. Luego nos quejamos de que los estudiantes copian, del que "bajan" la información de Internet, etc.; pero, eso sí, la presentan impecablemente en Word, versión milenium, impreso a color. El medio se rellena con cualquier cosa. Mientras el conocimiento estaría en aquello que se dice, independientemente de que sea impreso en láser o escrito a mano. En este aspecto, la escuela se puede pensar en función del trabajo conducente a que la gente tenga algo que decir; o en función de garantizar que, no importa lo que se diga, hay que decirlo "a la moda" (y entonces se convierte en un agente de ventas de Microsoft, pero que no gana comisión).

32 En la contracarátula de una videograbación, perteneciente a los programas a que nos estamos refiriendo, está escrita la siguiente curiosidad: «Esta excepcional colección de videos domésticos forma parte del continuo esfuerzo de National Geographic Society por incorporar la tecnología más avanzada a su misión educativa».

${ }^{33}$ Se trata de un ejemplo tomado de una investigación del llamado "Grupo Federici", de la Universidad Nacional, en el marco de un trabajo sobre la relación Escuela-Universidad.

34 Freud se expresa de una manera similar. En El malestar en la cultura, después de intentar una comparación para que se entienda su teoría, dice: «Nuestro intento parece ser un juego ocioso; su única justificación es que nos muestra cuán lejos estamos de dominar las peculiaridades de la vida anímica mediante una figuración intuible».

Digitalizado por RED ACADEMICA 
Recordaremos a ciertas administraciones educativas por el uso del Power Point, mecanismo para mostrar, de manera impecable, una serie de imprecisiones, para mostrar con el rigor de las barras y las curvas, una serie de datos de cuyo origen y procesamiento a veces ni siquiera el presentador sabe. En ausencia de esa herramienta, se puede ser más riguroso, aunque se sea menos "efectivo", que no es una preocupación del conocimiento, sino de la publicidad... Tal vez juzgamos la escuela con el rasero de la propaganda. Queremos ser tan efectivos como un videoclip musical, sin saber qué parte de esa forma estética es la que atrae al público.

El software, la innumerable información de Internet, sirven si hay algo que decir, que calcular, que organizar. De resto es una seducción a un interés que no es propiamente cognitivo. Los medios no producen por sí mismos el deseo de conocimiento. La naturaleza del conocimiento no se juega en los medios, sino en la problematización que bien se puede servir de los medios o que bien se puede ver subordinada o aplastada por ellos. El supuesto de que "hay muchas maneras de conocer" confunde el conocimiento con el hecho de que hay muchas fuentes de información ${ }^{35}$. Y con esa confusión muchas veces se sustenta la necesidad de los medios en educación, lo que no nos permite aprender gran cosa sobre el conocimiento, del que sin embargo decimos que es el objetivo primordial de la escuela. Para el hombre que empuña un garrote y para el que manipula un teclado de computador el asunto del conocimiento es idéntico, no así el de los recursos.

Lo que está en juego para comprender puede ocultarse detrás del medio. En ese sentido, Piaget [1971: 88] dice que los procedimientos audiovisuales «cuyas virtudes han sido celebradas por demasiados educadores, y que pueden conducir a una especie de verbalismo de la imagen, en realidad lo único que favorecen es las asociaciones, sin impulsar actividades auténticas». En una dirección similar se pronuncia Zuleta [1985: 2022]:

La educación hoy se hace lenguas con los avances de la tecnología educativa y los métodos audiovisuales. La educación está siendo pensada cada vez más con los métodos y los modelos de la industria. Ofrece una cantidad cada vez mayor de información, en el mínimo de tiempo y con el mínimo de esfuerzo [...] El que educa con estos sistemas no sabe lo que está haciendo, pero lo hace en el mínimo de tiempo, de la manera más rápida y menos costosa [...] confundiendo educación con información.

La ideología de la información ha producido una revolución en el campo educativo que es prácticamente una peste. Es allí donde queda más radicalmente reprimido el pensamiento como actividad

[...] Si el maestro aceptara que el niño o el joven es inteligente, y que puede enfrentarse con problemas complejos, entonces, en lugar de tanta figurita, tendría que exponer el concepto [de célula]; no presentar la imagen, porque la imagen no es el concepto, así se apoye o no en un dibujo, lo cual es secundario.

[...] Los métodos audiovisuales, o las imágenes, crean en el estudiante la ilusión de que sabe [qué es una célula], pero lo que ve es una raya en el tablero y un conjunto de nombres.

O sea, las ayudas didácticas pueden dirigirse hacia lo que satisface un gusto que no tiene que ver con el conocimiento. Querer ver imágenes en movimiento (seguir viendo TV en la

\footnotetext{
${ }^{35}$ En efecto, la información, rigurosamente hablando, está constituida sólo por señales, por unidades físicas, por tanto manipulables y transmisibles según los medios disponibles. Una de sus formas, sólo una, es la imagen, pero no la única [Eco, 1995: 41-42]. La información sirve, entre otras cosas, para intercambiar y difundir conocimiento, pero no necesariamente [Garassini y Gasparini, 1995: 127].
} 
escuela) no es necesariamente querer aprender. Satisfacer ese gusto no conduce forzosamente a alguien hacia el conocimiento. Puede incluso ser contraproducente para desarrollar conocimiento. En este sentido, los medios constituyen un caso de la llamada "motivación", pero el comentario se cumple para otras motivaciones que no implican tan claramente a los medios, como el premio y el castigo. O sea que mientras la escuela cree que "el fin justifica los medios", o peor, que "los medios ya son el fin", los estudiantes aplican la máxima de "los medios, no importa el fin".

Los saberes que maneja la cultura occidental son, en gran medida, producto de una época en la que no había los medios que están hoy a nuestro alcance. Acelerar la velocidad de tratamiento de los datos no modifica el conocimiento, modifica otras cosas que son importantes, pero que ya se mueven en un orden que no es el cognitivo. En su momento, el Ilamado "grupo Federici" se preguntaba lo que significaba introducir la informática a la escuela colombiana, siendo que en ella se podría echar de menos la introducción de la cultura escrita [Mockus et alii., 1985].

La queja de que alguien "no logró llamar nuestra atención", o el propósito de llamar la atención de nuestros alumnos, no son del orden del conocimiento, sino del entretenimiento. Haciendo una comparación con el conocimiento, Platón decía que médico y cocinero operan de manera contraria: mientras el cocinero debe hacer aparecer como atractivos los alimentos, incluso a riesgo de producir daños a largo plazo, el médico hace ingerir drogas de mal sabor, pero que producen la salud. Si el profesor busca producir efectos del lado del conocimiento, es como el médico. Si busca atraer la atención de los estudiantes, hacer agradable la enseñanza, está del lado del cocinero ${ }^{36}$. Así como el buen sabor no da lugar a la pregunta por las propiedades de lo ingerido, el formato medial se usa como ocultamiento e, incluso, como intimidación: ¿por qué dudar, qué preguntar, cuando nos dan tanta belleza?

Cuando aprendemos algo a partir de la imagen (no un simple hábito, sino un conocimiento), es gracias a los conceptos que se ponen en juego, y no por las imágenes mismas. Basta con tratar de explicar la Crítica de la razón pura, de Kant con imágenes, para entender que no es cierto - a nivel del conocimiento- que una imagen valga más que mil palabras. El hecho de que ese lema sí valga para la publicidad debería llamar nuestra atención en el sentido de qué está en juego allí. Hasta cierto punto, los lenguajes son irreductibles, de manera que tampoco es posible convertir una imagen en un discurso verbal. No se trata, entonces, de "lenguajes complementarios" —como decimos para justificar la introducción de los medios sin mayor discusión-, sino hasta cierto punto irreductibles. La unidad, si es que existe, estaría a nivel de un sujeto, más o menos evanescente, que hará algo con la información obtenida a través de esa diversidad de medios.

En todo caso, no se trata de niveles de significación, sino posiblemente de jerarquías, en tanto somos fundamentalmente seres hablantes, seres que pueden producir y manipular imágenes, pero no al contrario: no se puede hacer un ser humano con imágenes, sin palabras, y luego montar las palabras. El semáforo, en el que aparentemente sólo median las imágenes, fue inventado y funciona gracias a las palabras. Así mismo, para que sólo mediante un icono sea posible realizar una operación en el computador, sin tener que aprender comandos complejos en lengua escrita, es necesario que haya una programación, un diseño... cosas que ocurren fundamentalmente en la palabra escrita, así

36 No propendemos por una clase aburridora. La clase que pone en juego el conocimiento no entra en esa clasificación, pues pone en cuestión — lo que no es agradable-, pero abre posibilidades —lo que relanza el entusiasmo. 
el usuario no las vea; que el usuario se las ahorre, no indica que no existan. Si hay imágenes funcionales, las palabras están en algún lado, en algún momento, aunque no sean visibles.

\section{La interacción}

La educación está en relación con el conocimiento, pero en el marco de una interacción específica. Podemos decir que se conoce en el campo de la problematización del otro. El conocimiento sólo es demandado en un contexto cultural. Es un desafío del otro. De tal manera, podemos afirmar con Jerome Bruner [1971] que "aprendemos para no tener que aprender más". Esto quiere decir, al menos, un par de cosas que no tenemos en cuenta cuando confundimos la educación con medios:

De un lado, no es cierta nuestra supuesta apertura permanente al conocimiento, no es cierto que aprendamos de manera constante. Al contrario, Bruner explica que el conocimiento es una herramienta para dar lugar a otra cosa, para desocupar la atención. Si aprendiera algo cada vez que tengo que relacionarme con ello, no tendría tiempo para otra cosa. Aprendo eso y ahora puedo ocuparme de otra cosa, por ejemplo, del ocio. El aprendizaje es como una búsqueda que ha quedado condensada y que no tengo que volver a repetir en toda su extensión (aunque la haya construido), sino en la parte conclusiva que me interesa.

$Y$, de otro lado, la interacción con el otro muchas veces hace que esa explicación ya no sea del todo satisfactoria; ese contexto me obliga ("tener que") en el sentido de necesitar aprender de otra forma u otra cosa, para poderme liberar. Entonces, según esta idea de Bruner, un maestro preocupado por el conocimiento no es alguien que hace atractivo el aprendizaje, no es alguien que motiva, que da información. Más bien es alguien que causa el deseo en la medida en que incomoda la explicación existente, la que permite no hacerse una pregunta. El resultado es alguien causado por una interrogación, que puede dar sentido a la información, que puede seleccionarla con un criterio más allá del "gusto" o del "impacto" de su formato de presentación.

En este sentido, la información otorgada con los atractivos de los medios puede ser lo más lejano al conocimiento, en tanto no causa una pregunta, sino que se inscribe en lo sabido, por ejemplo, la rutina de las evaluaciones a la cual se le sabe sacar el cuerpo, o a la cual se sabe cómo responder sin conmover la posición del sujeto. Los textos escolares, para citar un caso, pueden ser usados para dispensar una educación gradual, con ejercicios, en fin, con todos los elementos supuestamente necesarios al alcance. En cambio, maestros que problematizan su área, los usan para mostrar las distintas versiones sobre los mismos hechos e, incluso, para mostrar cómo no entender algo, como no tratar los textos.

\section{La comunicación}

En las versiones actuales sobre la relación entre educación y comunicación, se suele esgrimir la idea de que hoy somos receptores y productores de información (input/output), condición que le da un lugar destacado a los medios, pues ante todo son instrumentos que hacen circular información. Tal idea, sin embargo, no solamente luce etnocentrista - 
es decir, como si Occidente fuera el mundo ${ }^{37}$ — , sino también "sincronocentrista", es decir, como si el mundo fuera comprensible siempre bajo las condiciones de hoy, como si las condiciones de hoy fueran permanentes. En realidad, no ha habido ni puede haber sociedad sin circulación de información, independientemente de la cantidad de información.

Por eso, si la cantidad de información circulante es muy poca, jeso no es un déficit!. El hecho de que circule esa cantidad de información tiene relación con la cultura de la que se trata, con sus posibilidades. Y ese mundo estará organizado con esos datos. Si nosotros necesitamos más información, pues la producimos, la buscamos, la acumulamos, y eso no es mejor. Sencillamente es distinto, adecuado a condiciones diferentes.

De otro lado, si en una sociedad la velocidad de circulación de la información es baja (comparada con la nuestra, por supuesto), pues tampoco se trata de una carencia. El hecho de que la información circule a esa velocidad se explica a partir de la cultura de la que se trata, que se las arregla con esa velocidad de movimiento informativo. Si nosotros necesitamos más velocidad, pues la producimos, la buscamos. Y eso tampoco es mejor, solamente es distinto, relativo a condiciones diferentes. Freud hablaba de esto en El malestar en la cultura:

\begin{abstract}
Hoy podemos escuchar la voz de un hijo que vive a cientos de kilómetros; saber apenas desembarcado- que un amigo pasó sin contratiempos un largo y azaroso viaje; disminuir la mortalidad de los recién nacidos. Pero, si no hubiera ferrocarriles que vencieran las distancias, el hijo no habría partido, y no haría falta teléfono alguno para escuchar su voz. De no haberse organizado los viajes transoceánicos, el amigo no habría emprendido ese viaje por mar y no necesitaríamos el telégrafo para calmar la inquietud por su suerte. Y haber limitado la mortalidad infantil, nos obliga a la reserva en la concepción de hijos, de suerte que en el conjunto no criamos más niños que en las épocas anteriores al reinado de la higiene.
\end{abstract}

Los medios disponibles son para una sociedad que los ha creado para responder a sus propias exigencias, de manera que lo interesante es entender esa cultura que ha requerido y producido los medios que más o menos obedecen a sus necesidades, y no obnubilarnos por las propiedades de unos medios que no pueden hacer más que aquello que es posible en esa cultura. La cantidad de información y la velocidad no son valores en sí mismos. De un lado, la cantidad nos tiene en este momento en una especie de nueva edad media: se trata del hecho de que si leyéramos durante 80 años continuos, 24 horas al día, sin interrupciones, alcanzaríamos a abordar el $3 \%$ de lo que está escrito. Cualquiera puede verificarlo fácilmente cuando introduce una palabra en un buscador de Internet: generalmente hay millones de referencias, que ningún ser humano sería capaz de aprehender. Tenemos mucha información, pero inalcanzable. Y, por su parte, la velocidad está amarrada a una sociedad para la que el tiempo expresa la múltiple conectividad existente entre sus sistemas, la dependencia que se da entre ellos. No obstante, no somos capaces de aprender más rápido. Aumentar la velocidad de la transmisión de datos no aumenta la velocidad para aprender. Quizá nos haga esperar menos ciertos datos que están en función de nuestro conocimiento, pero ese tiempo de supuesta espera era antes un tiempo productivo alterno.

37 Es el caso de creer que nuestro año 2000 era el cambio de milenio para la humanidad, cuando más de la mitad de ella tiene una contabilidad distinta del tiempo histórico. 
Nuestras clases de hoy no son cualitativamente superiores al paseo de Sócrates con Hipias para conversar sobre lo bello. Quizá nuestros alumnos ni siquiera aprendan, no obstante disponer de medios. En todo caso no aprenderán más, porque la problematización propia al conocimiento no es cuantificable, se mide como cambio de posición que, entre otras, requiere para cada uno un tiempo propio.

Así, la comunicación no es un componente pedagógico. Eso se dice para curricularizar la comunicación, para aplicarle la motivación, etc. Más bien habría que plantear que la pedagogía es comunicación por definición, y usa para ello lo que esté disponible.

\section{Los medios, ¿mejoran la calidad de la educación?}

Para que resulte indiscutible cierta política educativa que comprometa los medios, hoy se hace necesario mencionar su positiva relación con la "calidad de la educación". En el ámbito educativo, generalmente las palabras circulan como nociones que no se interdefinen, que se amontonan, que puedan estar de moda, dejar de estar, volver a estar. Pero no es ésta una condición necesaria de la educación. Los maestros que la entienden como un espacio con una relación posible con el conocimiento trabajan en su seno con la idea de que las palabras sean categorías, es decir, que dependan de un orden conceptual, que se definan entre sí, que no basta con yuxtaponerlas. Así, la palabra "calidad" pertenece a las nociones y no a las categorías. Cuando se la usa, no se demuestra qué es, porque al público a quien se le dirige se le supone ese saber y él, a su vez, no quiere poner en consideración si sabe o no el asunto. En consecuencia, se forma el más extraño consenso. Extraño porque proviene justamente de la ausencia de discusión, de explicitación de criterios.

Tal como en las propagandas de televisión, parecen producirse mágicamente ciertos efectos: así como un cigarrillo te da felicidad, los medios producen calidad educativa. Nada más improductivo, si de entender la educación se tratara. Nada más vacío si la política educativa en realidad fuera un intento de cualificar la educación y no la aplicación, en el orden político, de ciertas medidas que no son acordadas en función de bondades educativas, cognitivas, pedagógicas o epistemológicas, sino más bien en función de planes de reducción de costos, de eficiencia, de reducción de planta de personal, etc.

¿Qué es "calidad de la educación"? En primera instancia, es una palabra. Una expresión que viene desde hace 20 años, acompañada de una serie de medidas adjuntas: evaluación y medición, planes de "mejoramiento", introducción de un lenguaje de "eficiencia y eficacia", supuesta demostración de que lo oficial no funciona, transformación de las funciones del Estado, privatización, disminución de las ventajas contractuales que han ganado los docentes, etc.

Si de cuenta de los agentes educativos preocupados por el conocimiento hubiera estado la idea de calidad, seguramente no habría estado lejana de "aquello que se pone como problematización". Si, como dijimos atrás, se aprende para no tener que aprender más, el papel del maestro está en no dar consistencia a lo sabido, para lo cual él mismo debe estar en esa posición, única que daría lugar a desear el saber. "Calidad", en tal condición, es poner lo mejor de uno para que el saber tenga que ser discutido, ensayado, replanteado, entendido en su dimensión histórica. En cuyo caso, el mejor regalo que se le puede hacer a una escuela no es un buen aparato, sino un buen maestro... claro que si, además, hay buenos aparatos, no hay problema. 
Podemos darnos por bien servidos si hay buenos profesores, aunque no haya buenos medios, pero no a. revés: no podemos darnos por bien servidos si hay buenos aparatos, a pesar de que no haya buenos profesores. No se trata de una negativa a los medios, sino de su real aprovechamiento, en dirección a una finalidad cognitiva. A quien le parece que no habría que perderse los aparatos, pese a que no haya una buena condición docente, no le interesa el sentido de la educación, sino su apariencia.

Claro que aquí se forma una tautología, pues se puede decir: "los niños formados con ayuda de estos aparatos tuvieron mejores resultados en la evaluación de la calidad". Pero, las pruebas autodenominadas "evaluación de la calidad", ¿acaso miden el conocimiento? Toda forma educativa impondrá una manera de entender la escuela y después la medirá con arreglo a esos mismos criterios. Por ejemplo: quien cree que la calidad es cantidad de información, evalúa eso y obtiene comparaciones bajo ese criterio.

Para salir del círculo, entonces, no nos sirve mucho presuponer lo que es "calidad", sino más bien discutirlo. Es más: si no podemos prescindir de esa palabra para pensar la educación $^{38}$, al menos es necesario crear un ámbito para discutir permanentemente lo que entendemos por una educación de calidad. Mantener abierta la discusión, no llegar a definiciones terminantes. Ahora bien, si de algo carecen este tipo de evaluaciones es de una definición de "calidad". Y, si la dieran, sería: "puntaje obtenido en las pruebas para medir la calidad", es decir, otra tautología: ¿qué es calidad?: lo que miden las pruebas; ¿qué miden las pruebas?: calidad. También habría respuestas del lado de la eficiencia y la eficacia, del costo per capita, etc., que ya resultan inservibles para pensar la especificidad de la educación ${ }^{39}$, y sobre todo para pensarla en contextos históricamente determinados.

Un ejemplo de cómo la evaluación, más que medir, produce una nueva realidad educativa es el hecho que se presentó con ocasión de los resultados en la evaluación de "competencias básicas" en el DC. Los investigadores que se mueven alrededor de los resultados de las pruebas, afanados por saber sobre las prácticas de una maestra oficial que, contra la tendencia promedio, tuvo excelentes resultados en una escuela ubicada en una zona económicamente deprimida, fueron a interrogarla. Las "prácticas exitosas" como se dice en la jerga de la política educativa- de la maestra, según su propia declaración, eran conseguir pruebas y entrenar a los estudiantes en su resolución.

En conclusión, si el peso de la educación recae sobre los maestros, en tanto que con su posición estructuran las posibilidades del sentido circulante en la educación, la preocupación fundamental debería estar en su formación. Formación inicial, en ejercicio, etc., que también depende de las condiciones que el gobierno ha puesto y que delimitan la constitución del rol de maestro. Por supuesto que, nadie se va a negar a que haya los mejores medios posibles, juzgados a partir del sentido construido en ese contexto, pero lo cierto es que en muchos casos cierto énfasis en los medios coincide con una desconfianza en los maestros. En pocas palabras: como no tienen una buena formación y como es muy dispendioso, lento y costoso capacitarlos, entonces grabemos la educación y que ellos ayuden a tramitar los pasos diseñados en otra parte y a servir de tutores, de

${ }^{38}$ Sabemos que la noción de "calidad" pasa a la educación proveniente de una dinámica empresarial que se quiere imprimir a la escuela. Pero esa no es razón suficiente para sacarla del ámbito educativo —que introduce y saca palabras sin tener en cuenta criterios académicos-. Lo interesante es saber por qué una palabra que viene de la fábrica ha entrado con tanto éxito (frecuencia de uso) en la educación.

39 Evidentemente, los costos, el buen uso de los recursos, etc., son necesarios para pensar la educación por parte de quienes determinan la política, de quienes tienen que destinar recursos, etc., pero esa dimensión no es toda la educación. Es más, esa dimensión -administrativa, digamos- del asunto supuestamente está al servicio de la especificidad educativa. 
auxiliares del material. Esta situación no es desconocida en nuestro país: la época del "diseño instruccional" se basó exactamente en los mismos presupuestos.

Los medios, como en el caso de educación por televisión, se prestan para ideas de ampliación de cobertura sin ampliación de la nómina docente (en un contexto de ajuste fiscal), a nombre de una calidad indefinida y medida con el mismo mecanismo que la supone constituida por cierto tipo de información.

\section{Hacemos lo que podemos}

La historia de la relación entre medios y educación es muy interesante. De acuerdo con la investigación de Alejandro Álvarez [2003]: a) algunas de las ideas actuales en relación con los medios se vienen planteando desde hace un siglo, b) el efecto de los medios en la educación siempre ha sido independiente de los propósitos educativos, c) la escuela ha terminado transformada en un sentido no previsto, d) lo ocurrido ha tomado a la escuela sin quién la piense, y e) paradójicamente, siempre ha quedado algo que la hace todavía vigente.

Durante el siglo pasado, a) se pensó que el hombre tipográfico, con una imagen lineal y fragmentada de la realidad, producto de caracteres separados y fatigantes, cedería su papel al hombre audiovisual, con una visión integral, multifacética y sensitiva, usuario de iconos atractivos y económicos... Sin embargo, de esto sólo sucedió lo que históricamente era posible, y un siglo después creemos que la idea es una innovación en educación. b) Se pensó que ya no habría maestro transmisor, sino creador de climas socioafectivos, diseñador, conocedor del aprendizaje, experto en utilizar las máquinas y que el alumno dejaría de ser receptor y pasaría a relacionar, analizar, sintetizar, hipotetizar, interpretar, escoger, decidir... Sin embargo, esto no sucedió y la impresión de lo que la escuela es no ha cambiado, así como el sentido de la transformación que supuestamente requiere. c) Se pensó que con los medios, se enseñaría fuera del aula, sin maestro, se complementaría y hasta reemplazaría la educación formal, y con más cobertura... Sin haberlo logrado, estas siguen siendo las pretensiones de utilizar los medios para ahorrar costos. d) Se pensó que una masificación con individualización exigía actuar pedagógicamente: programar, organizar, coordinar, hacer progresión... Algo que se sigue pidiendo hoy al uso de los medios con fines educativos.

De otro lado, se habla de los medios como si su materialidad implicara un solo sentido. Sin embargo, dependiendo de la concepción de escuela — según el sentido de la actividad se centre en cierto aspecto-, la utilización de los medios les otorga un sentido variable:

- Cuando se concibe que la acción educativa se aplica principalmente a objetos o con objetos (visión instrumental de la escuela), los medios son muy importantes, tal vez la razón fundamental, y su llegada parece dar soporte a esa concepción. Los medios tendrían un sentido per se, no lo ganarían. Bajo esta perspectiva, se justifica la idea de que los medios mejoran la calidad educativa, de que a más y mejores medios, mejor educación. Es lo que cierta publicidad oficial maneja en la campaña de donación de computadores para la educación. Por su parte, la investigación oficial sobre "factores asociados" da consistencia a esta postura de la objetividad de ciertos factores (entre ellos los medios), independientemente de su inserción particular en un contexto históricamente determinado.

- Cuando se concibe que la acción educativa se aplica principalmente a personas (visión estratégica de la escuela), la importancia de los medios radica en su utilidad para que los otros — que no saben, no pueden, no quieren-lleguen a los propósitos 
que unos - que saben, pueden, quieren - se han trazado y que ya han superado. El fin justifica los mass media. Se usan porque, de otra manera, la educación no resultaría atractiva, o sería muy lenta, o le faltaría información (es lo que maneja otra publicidad oficial) etc. Es decir, no se cumplirían ciertos objetivos previos, generales, que alguien se traza para otro.

- Y cuando se concibe que la acción educativa se aplica principalmente al sentido (visión comunicativa de la escuela), los medios se convierten en un mecanismo para tramitar las inquietudes cognitivas, para hacer posible la conversación permanente sobre la manera como los conocimientos han devenido dignos de estar en la escuela, como las relaciones se han ido tejiendo y legitimando, etc. En este caso, se busca explicitar el sentido que adquieren los medios mismos, no el sentido que tendrían per $s e^{40}$.

De esta manera, si el valor de los medios emerge en función del sistema de pensamiento históricamente determinado que vienen a apuntalar, entonces no sólo los medios no tendrían un sentido único, derivado de un valor intrínseco, sino que los propósitos en relación con los medios caen en el vacío cuando se promulgan para una escuela homogénea, en la que todos piensan igual y en la que no hay diversos intereses. Requerimos los medios, pero también requerimos los análisis que muestren - desde la perspectiva que sea- una escuela diversa, heterogénea, permeable a las diferencias e intereses sociales. Requerimos una vida escolar que problematice su relación con el saber, con la interacción, con la comunicación, con la sociedad de la que hace parte, que utilice los medios para lograrlo, y que someta esos medios a la misma mirada que haría posible una escuela de tal naturaleza.

\section{Referencias bibliográficas}

Álvarez, Alejandro. Los medios de comunicación y la sociedad educadora. ¿Ya no es necesaria la escuela? Bogotá: Magisterio-UPN, 2003.

Bachelard, Gaston. La filosofía del no (1948). Buenos Aires: Amorrortu, 1973. La formación del espíritu científico (1948). México: Siglo XXI, 1979.

Bernstein, Basil. "La educación no puede suplir las fallas de la sociedad", en Lenguaje y sociedad (varios autores). Cali: Univalle, 1983.

La estructura del discurso pedagógico (1990). Madrid: Morata, 1993.

Brunner, Jerome. "Aprendizaje y pensamiento", en (varios Autores) Aprendizaje escolar y evaluación (1971). Buenos Aires: Paidós, 1984.

La importancia de la educación (1971). Barcelona: Paidós, 1987.

Elkana, Yehuda. "La ciencia como sistema cultural. Una aproximación antropológica" (1977), en Boletín de la sociedad colombiana de epistemología. Bogotá, Vol. III, No. 10-11, enero-diciembre, 1983.

Federicci, Carlo et alii. "Lenguaje, voluntad del saber y calidad de la educación", en Revista Educación y Cultura, No.12. Bogotá: FECODE, junio de 1987.

40 Para cualquiera, es mejor que haya libros en una escuela a que no haya. Sin embargo, la investigación de Otálora y otros [1993] encontró que los libros adquieren un sentido, dependiendo del proyecto de la institución. De manera que es mejor que un sentido promueva a la existencia los libros que, de otra manera, son papel impreso y, a lo sumo, recursos para hacer tareas cuyo sentido acaba con la sanción del profesor. 
. "Límites del cientificismo en educación" en Revista colombiana de educación. Bogotá: UPNCIUP, No. 14, II semestre de 1984.

Freud, Sigmund. "El malestar en la cultura" (1932), en Obras completas. Buenos Aires: Amorrortu, Tomo XXI, 1990.

Mockus, Antanas et alii. "¿Informática sin escritura? El problema para la educación” (1985), en Los procesos de la escritura. Jurado, Fabio, y Bustamante, Guillermo, comp. Bogotá: Magisterio, 1996.

. Las fronteras de la escuela. Bogotá: SOCOLPE, 1994.

Otálora, Blanca et alii. "El uso de materiales educativos en la educación secundaria". Bogotá: Instituto Ser de investigación, s. p., 1993.

Sábato, Ernesto. Uno y el universo. Buenos Aires: Sudamericana, 1984.

Sagan, Carl. Cosmos.

Zuleta, Estanislao. "La educación: un campo de combate" (1985), en Educación y democracia. Medellín: Hombre Nuevo, 1995.

. Lógica y crítica (1976). Medellín: Hombre Nuevo, 2003. 